\title{
INFORMATION TECHNOLOGY GOVERNANCE AND ACCOUNTING PERFORMANCE ON FIRM PERFORMANCE OF THAI-LISTED FIRMS
}

\author{
Aukkaradej Chaveerug, Mahasarakham University, Thailand \\ Amarit Sompong, Mahasarakham University, Thailand
}

dx.doi.org/10.18374/JIBE-13-3.3

\begin{abstract}
The objective of this research is to examine the relations between Information Technology Governance on Firm Performance via Accounting Discloser Quality, Accounting Information Transparency, Accounting Information Valuable and Accounting Performance. Data collection is done by sending the questionnaires to chief financial officer in Thai-Listed Firms; measurements of constructs both the validity and reliability use the Ordinary Least Squares (OLS) regression analysis to test the hypotheses relationship and estimate factors affecting the Firm Performance. The results show the Information Technology Governance has positive relationships with Accounting Discloser Quality, Accounting Information Transparency, Accounting Information Valuable and Firm Performance. Theoretical, managerial and research implications are also discussed.
\end{abstract}

Keywords: Information Technology Governance, Accounting Discloser Quality, Accounting Information Transparency, Accounting Information Valuable, Accounting Performance, Firm Performance 